\title{
CVD diamond layers for electrochemistry
}

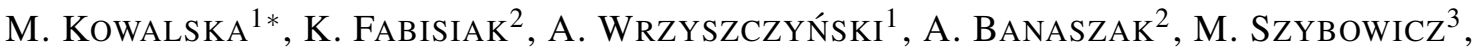 \\ K. PAPROCKI ${ }^{2}$, W. BAEA ${ }^{2}$, F. B YLICKI ${ }^{2}$ \\ ${ }^{1}$ Faculty of Chemical Technology and Engineering, University of Technology and Life Sciences, Seminaryjna 3, 85-326 \\ Bydgoszcz, Poland \\ ${ }^{2}$ Institute of Physics, Kazimierz Wielki University, Powstańców Wielkopolskich 2, 85-090 Bydgoszcz, Poland \\ ${ }^{3}$ Faculty of Technical Physics, Poznan University of Technology, Nieszawska 13A, 60-965 Poznań, Poland
}

\begin{abstract}
Diamond electrodes of different morphologies and qualities were manufactured by hot filament chemical deposition (HF CVD) techniques by changing the parameters of diamond growth process. The estimation of diamond quality and identification of different carbon phases was performed by Raman spectroscopy measurements. The effect of diamond quality and amorphous carbon phase content on the electrochemical response of an obtained diamond electrode in $0.5 \mathrm{M} \mathrm{H}_{2} \mathrm{SO}_{4}$ as supporting electrolyte was investigated by cyclic voltammetry with $\left[\mathrm{Fe}(\mathrm{CN})_{6}\right]^{4-/ 3-}$ as a redox probe. The kinetic parameters such as catalytic reaction rate constant $\mathrm{k}_{0}$ and electron transfer coefficient $\alpha$ were determined. The obtained results show that the analytical performance of undoped diamond electrodes can be implemented just by the change of diamond layers quality.
\end{abstract}

Keywords: cyclic voltammetry; Raman spectroscopy; undoped diamond layer; amorphous carbon phase

(C) Wroclaw University of Technology.

\section{Introduction}

Diamond is a very resistant to chemical attack and corrosion-stable electrode material suitable for electrochemical and environmental-oriented electrochemical applications [1]. Electrical conductance is an important feature when it is planned to be applied in electrochemistry. The easiest way to make diamond conductive is doping with boron [2] however, the doping is not a unique way to make diamond conducting [3]. The first paper on the electrochemistry of non-diamond layers grown by CVD method, whose conductance was attributed to some structural defects formed in crystallites in the course of the growth process, and which played the role of acceptors rather than to intercrystallite boundaries, was published by the group of Yuri V. Pleskov [4].

It is well known that the as-grown CVD diamond film is always hydrogen terminated [5], which generates p-type conductivity restricted to the surface region $(10 \mathrm{~nm})[6]$ on the grain bound-

\footnotetext{
*E-mail: lenakow@utp.edu.pl
}

aries and gives possibility to use the diamond layer as an electrode material in electrochemistry. The amorphous carbon admixture and hydrogen terminated diamond grains are responsible for an electrical contact not only between diamond grains but also between the diamond layer and the substrate [7]. The diamond layers grown on different substrates have a particular importance for electrochemical applications because they offer high sensitivity, good precision and high stability, when compared with other commonly used electrodes such as glassy carbon and platinum. The potential window of diamond electrodes with respect to hydrogen and oxygen evolution in aqueous solution is very large, which may favor the analysis of alternative reactions in this medium. Thus, diamond electrodes can be employed for electrosynthesis and electroanalysis [8-10].

The electrochemical behavior of a diamond layer depends on the perfection of its crystal structure, the concentration of grain boundaries (GBs) and impurities, which determine its conductance [11]. In general, the diamond electrode behavior depends on particular conditions of its 
growth: these determine the size of crystallites, their perfection, the structural defect concentration, amorphous carbon phase admixture, etc. [12].

In the present work we studied the electrochemical properties of undoped polycrystalline diamond films produced by hot filament chemical vapor deposition (HF CVD).

\section{Experimental}

The undoped polycrystalline diamond films were synthesized by HF CVD technique using a tungsten wire, $0.5 \mathrm{~mm}$ in diameter, as a substrate. As a working gas the mixture of methanol vapor and hydrogen $\left(\mathrm{CH}_{3} \mathrm{OH} / \mathrm{H}_{2}\right)$ was used. The parameters of the growth process, i.e. total pressure in reaction chamber and ratio of methanol/hydrogen gas, were changed in order to obtain the proper diamond layer, while other parameters such as for example substrate temperature and working gas flow rate were fixed constant. The details of the growth are described by Fabisiak et al. [13].

The diamond film morphology has been studied by Jeol JSM-820 SEM microscope.

The phase composition of obtained diamond layers was determined by Raman spectroscopy measurements. The Raman spectra were recorded at room temperature in backscattering geometry using Renishaw inVia Raman spectrometer. The $488 \mathrm{~nm}$ line from argon laser was used for excitation. The cyclic voltammograms were recorded by CS-1087 computer controlled potentiostat (Cypress System Inc., Lawrence, KS) in a threeelectrode configuration. A platinum served as a counter- and $\mathrm{Ag} / \mathrm{AgCl} / 0.5 \mathrm{M} \mathrm{H}_{2} \mathrm{SO}_{4}$ served as a reference electrode, respectively.

\section{Results and discussion}

The SEM pictures of diamond layers synthesized on tungsten wire (1 $\mathrm{mm}$ in diameter) at different methanol concentrations are presented in Fig. 1. In order to compare the morphologies, the pictures were taken at the same magnifications. Fig. 1a presents a diamond layer composed from crystallites having well defined crystal features.
As methanol concentration increased, the grain sizes decreased (Fig. 1b and 1c) and the concentrations of GB's increased.
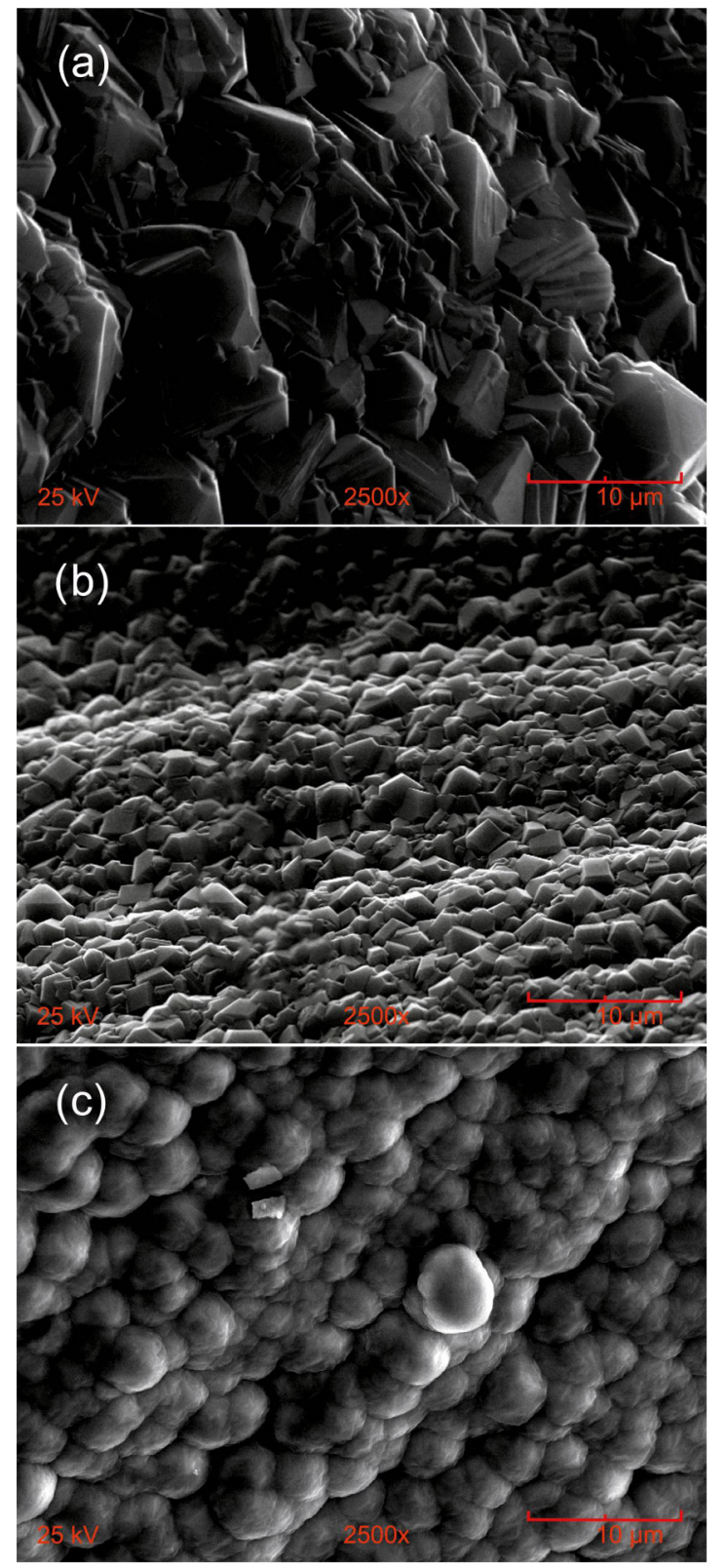

Fig. 1. Morphology of diamond layers obtained at different methanol concentrations: (a) $0.5 \%$, (b) $2.3 \%$, (c) $4.74 \%$.

Above observations were confirmed by Raman spectroscopy measurements shown in Fig. 2.

As one can observe, the presented Raman spectra differ significantly from each other. The spec- 

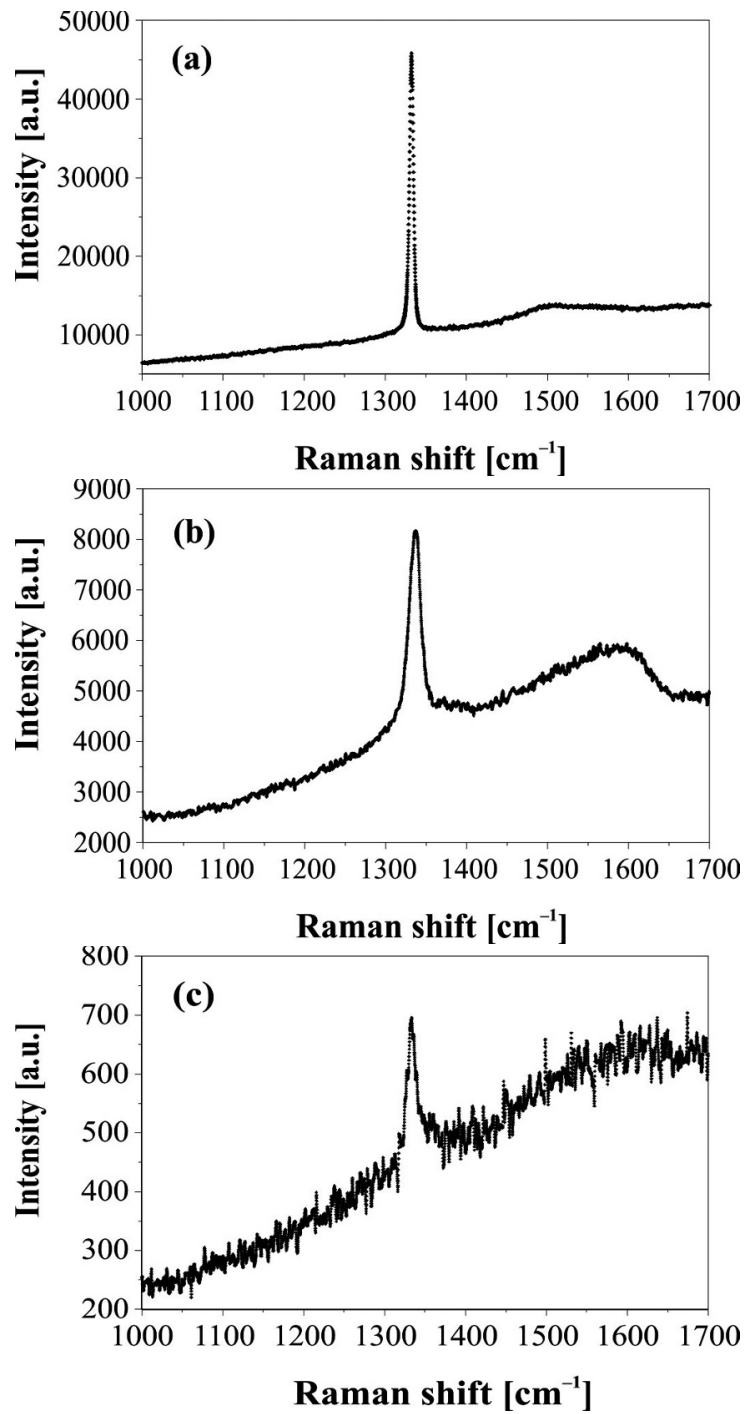

Fig. 2. Raman spectra of diamond layers presented in Fig. 1.

trum in Fig. 2a shows a sharp diamond Raman line at $1332.2 \mathrm{~cm}^{-1}$ on an almost flat background. The two remaining spectra, except a sharp diamond line, show a broad band at $1530-1580 \mathrm{~cm}^{-1}$ called G-line indicating that the diamond layer contains an admixture of amorphous carbon phase, including $\mathrm{sp}^{2}$ hybridized carbon phase, which is confirmed by the FWHM (full width at half maximum of peak) of this band. The parameters of presented Raman spectra are collected in Table 1.

The concentration of amorphous carbon phase was estimated according the procedure described by Banaszak et al. [12]. From Table 1 it is clearly
Table 1. The parameters of Raman spectra from Fig. 2.

\begin{tabular}{lccc}
\hline Electrode Diamond Raman & $\begin{array}{c}\text { Diamond } \\
\text { line position } \\
{\left[\mathrm{cm}^{-1}\right]}\end{array}$ & $\begin{array}{c}\text { Raman FWHM } \\
{\left[\mathrm{cm}^{-1}\right]}\end{array}$ & \\
\hline \hline WC (a) & 1332.2 & 6.1 & 0.3576 \\
WD (b) & 1333.6 & 12.8 & 0.5211 \\
WF (c) & 1334.4 & 13.7 & 1.3208 \\
\hline
\end{tabular}

seen that with decreasing of the diamond quality (FWHM increases), the concentration of amorphous carbon phase increases.

The cyclic voltammetry (CV) measurements were carried out in a single compartment, threeelectrode system, which consisted of a microcrystalline diamond electrode as a working electrode, an $\mathrm{Ag} / \mathrm{AgCl}$ as a reference electrode, and platinum wire as a counter electrode. The cyclic voltammograms of the diamond electrodes in $0.5 \mathrm{M}$ $\mathrm{H}_{2} \mathrm{SO}_{4}$ electrolytes containing $[\mathrm{Fe}(\mathrm{CN}) 6]^{3-/ 4-}$ were recorded. The scan rate was set as $0.1 \mathrm{~V} / \mathrm{s}$ and the concentration range of $[\mathrm{Fe}(\mathrm{CN}) 6]^{3-/ 4-}$ was $0.001-0.02 \mathrm{M}$.

The voltammograms of the diamond electrodes described above are shown in Fig. 3.

All presented voltammograms show symmetrical oxidation and reduction peaks. The couple's redox behavior was tested at different diamond electrodes (Fig. 3) in order to calculate the kinetic parameters of the reaction. The redox system was irreversible at all diamond electrodes (peak separation $\Delta \mathrm{E}_{p}>59 \mathrm{mV}$ for 1 electron). Both oxidation and reduction peaks exhibited the typical trend of irreversible systems following the equation that relates the peak potentials $-\mathrm{E}_{p}$ - and the half-peak potential $-\mathrm{E}_{p / 2}$.

All electrodes worked properly, i.e. the peak current increased proportionally to the redox couple concentration and fulfilled the Randles-Sevcik law [14]:

$$
I_{p}=2.69 \cdot 10^{5} n^{\frac{3}{2}} D_{0}^{\frac{1}{2}} A \cdot C_{0}
$$

where: $\mathrm{I}_{p}$ - peak current, $(\mathrm{n}=1$ for single charge transfer), A - effective electrode area, $\mathrm{C}_{0}$ - bulk concentration. 

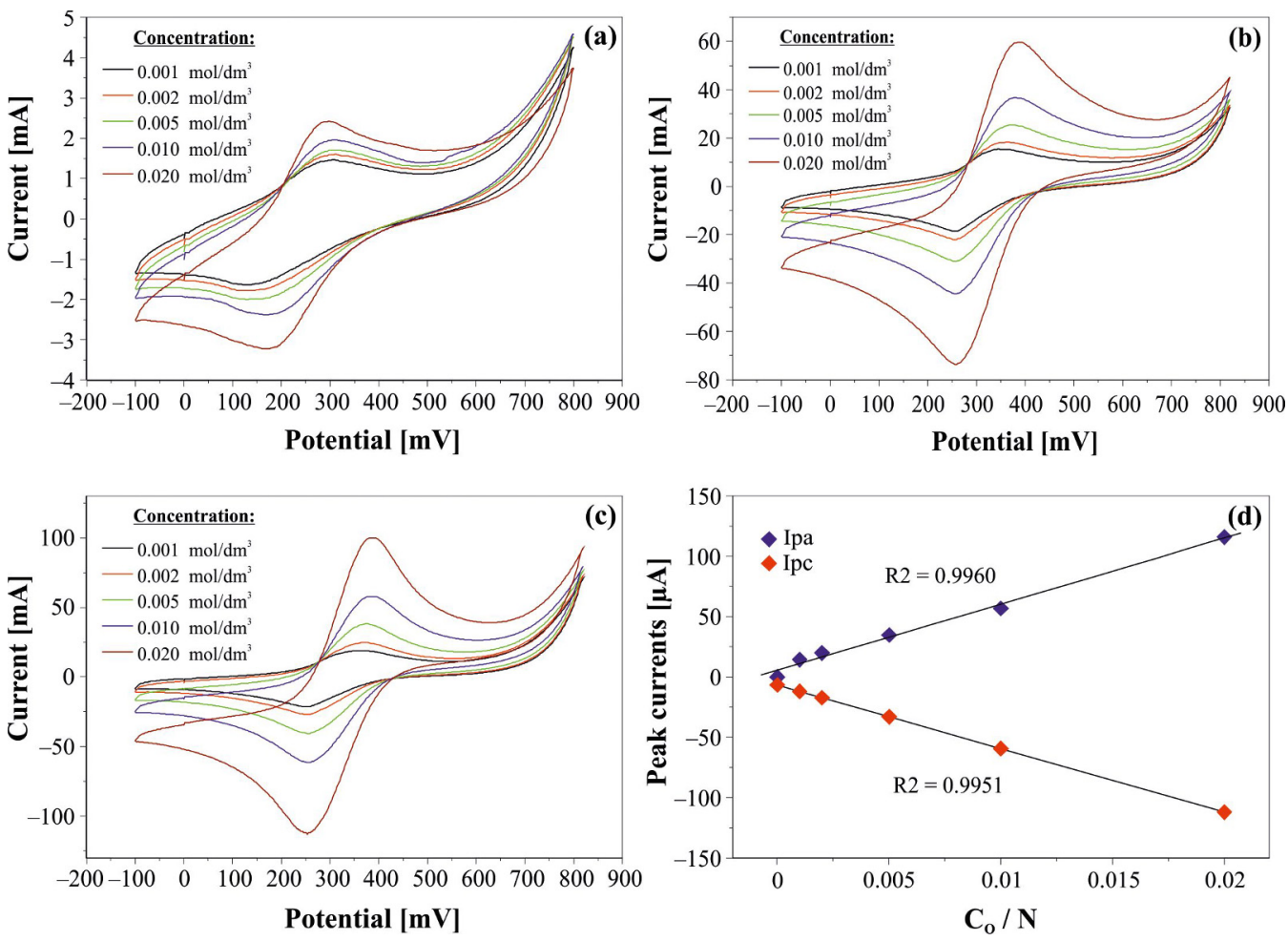

Fig. 3. The voltammograms of the electrodes from Fig. 1. Fig. 3d shows the peak current vs. redox couple concentration for Fig. 3c.

Fig. $3 d$ presents the dependence of $I_{p}$ vs. $C_{0}$ for voltammograms from Fig. 3c.

The transfer coefficients $\alpha$ were calculated for all electrodes from the equation:

$$
E_{p}-E_{p / 2}=1.857 \frac{R T}{\alpha F}
$$

where: $\mathrm{F}$ - Faraday constant, $\mathrm{T}$ - temperature, $\mathrm{R}$ universal gas constant.

The kinetic parameters of the ferri/ferrocyanide redox process were also determined by polarising the electrode surfaces. The polarisation curves of Fig. 4 show a good symmetry between the anodic and the cathodic reaction. Fig. 4 represents polarisation curves for the electrode from Fig. 1a, the other electrodes show similar linear behavior but have different slopes. The polarisation curves were fitted to straight lines, the slopes of which increased linearly with the concentration of the species.

The potential of an electrode strongly affects the kinetics of all faradaic processes occurring on its surface. The phenomenological model of Butler

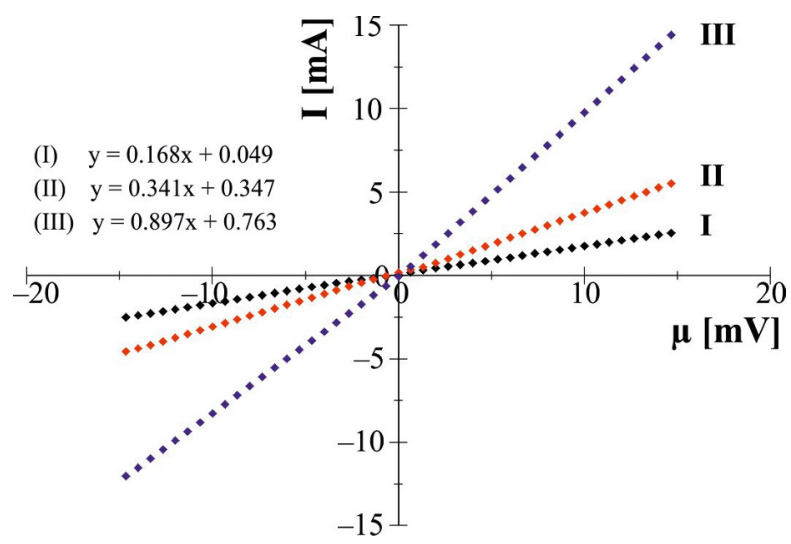

Fig. 4. Polarisation curves for the $\left[\mathrm{Fe}(\mathrm{CN})_{6}\right]^{3-/ 4-}$ system at the diamond electrode from Fig. 1c, at different concentrations: (I) $0.001 \mathrm{M}$, (II) $0.005 \mathrm{M}$, (III) $0.020 \mathrm{M}$.

and Volmer [15] is able to relate the reaction rate (current density) with the applied electrode potential using two parameters ( $\mathrm{k}_{0}$ or $\mathrm{j}_{0}$ and a). If the solution is well stirred or the current is so low that the surface concentration does not differ from the bulk 
value, the Butler and Volmer equation becomes:

$$
i=i_{0}\left(e^{-\alpha_{\text {red }} \frac{F}{R T} \eta}-e^{\beta_{o x} \frac{F}{R T} \eta}\right)
$$

where: $\alpha_{\text {red }}, \beta_{o x}-$ transfer coefficients for reduction and oxidation processes, respectively.

For small overpotentials $\eta\left(\eta=\mathrm{E}-\mathrm{E}_{e q}\right)$ the above equation can be simplified to the following form:

$$
i=i_{0} \frac{F}{R T} \eta
$$

From the dependence $i$ vs. $\eta$ we can estimate the value of $i_{0}=\frac{F}{R T}$ and reaction rate constant $\mathrm{k}_{0}$ according to formula:

$$
k_{0}=\frac{i_{0}}{F C_{0}}
$$

The calculated values of $\alpha, \Delta \mathrm{E}_{p}$ and $\mathrm{k}_{0}$ are collected in Table 2.

Table 2. Reaction parameters of the redox system $\left[\mathrm{Fe}(\mathrm{CN})_{6}\right]^{3-/ 4-}$ at diamond electrodes.

\begin{tabular}{cccc}
\hline Electrode & $\begin{array}{c}\Delta \mathrm{E}_{p} \\
{[\mathrm{mV}]}\end{array}$ & $\alpha$ & $\begin{array}{c}\mathrm{k}_{0} \\
{[\mathrm{~cm} / \mathrm{s}]}\end{array}$ \\
\hline \hline $\mathrm{a}$ & 140 & 0.34 & $2.410^{-4}$ \\
$\mathrm{~b}$ & 136 & 0.36 & $4.910^{-3}$ \\
$\mathrm{c}$ & 128 & 0.37 & $6.810^{-3}$ \\
\hline
\end{tabular}

The results indicate that the reaction rate constant on the diamond electrode depends on nondiamond carbon surface species ( $\mathrm{sp}^{2}$ inclusions) incorporated into the diamond structure.

The peak separation $\Delta \mathrm{E}_{p}$ and transfer coefficient $\alpha$ slightly depend on diamond quality.

\section{Conclusions}

The electrochemical activity of the diamond layers was strongly influenced by the surface morphology and amorphous carbon admixture. The diamond of low concentration of $\mathrm{sp}^{2}$ carbon phase had a low activity toward redox couple, whereas the electrode activity increased with increasing $\mathrm{sp}^{2}$ concentration. The $\mathrm{sp}^{2}$ concentration had a weak influence on the values of $\Delta \mathrm{E}_{p}$ and the transfer coefficients $\alpha$ but it had an essential influence on reaction rate $\mathrm{k}_{0}$.

The model proposed by Martin et al. [16] can be used to describe the effect of the $\mathrm{sp}^{2}$ species on the electrochemical behavior of diamond electrodes. The diamond electrode can be described as a composite electrode consisting of a non-active matrix of polycrystalline diamond ( $\mathrm{sp}^{3}$ carbon), in which species ( $\mathrm{sp}^{2}$ carbon) are present. The $\mathrm{sp}^{2}$ carbon species can be considered as the primary pathway for the charge transfer process, assuming that electron transfer is much more significant at nondiamond than at diamond sites.

\section{References}

[1] Varney M.W., Aslam D.M., Janoudi A., Chan H.-Y., WANG D.H., Biosensors, 1 (2011), 118.

[2] Madaleno J.C., Trippe S.C., Pereira L., Diam. Relat. Mater., 16 (2007), 926.

[3] FABisiak K., TORZ-Piotrowska R., Staryga E., Szybowicz M., Paprocki K., Banaszak A., Popielarski P., Mater. Sci. Eng. B-Adv., 177 (2012), 1352.

[4] Pleskov Y.V., Sakharova A.Y., Krotova M.D., Boullov L.L., B. V. SpITSYN, J. Electroanal. Chem., 228 (1987), 19.

[5] Ballutaud D., Jormand F., Kociniewski T., RzepKa E., Girard H., SAada S., Diam. Relat. Mater., 17 (2008), 451.

[6] Rakha S.A., Jianging C., Huihao X., Guojun Y., Zhu D., Gong J., Diam. Relat. Mater., 18 (2009), 1247.

[7] Torz-Piotrowska R., FABisiak K., PAProcki K., Szybowicz M., Staryga E., BANASZAK A., $J$. Phys. Chem. Solids, 72 (2011), 1225.

[8] Spicka H., Griesser M., Hutter H., GrasserBauer M., Bohr S., Haubner R., Lux B., Diam. Relat. Mater, 5 (1996), 383.

[9] Popovici G., Prelas M.A., Diam. Relat. Mater, 4 (1995), 1305.

[10] Brandes G.R., Beetz C.P., Feger C.A., Wright R.L., Diam. Relat. Mater., 4 (1995), 586.

[11] Pleskov Y.V., Usp. Khim., 68 (1999), 427.

[12] BanaszaK A., FabisiaK K., Kaczmarski M., Kozanecki M., Cryst. Res. Technol., 41 (2006), 535.

[13] Fabisiak K., SZReiber M., Uniszkiewicz C., Runka T., Kasprowicz D., Cryst. Res. Technol., 45 (2010), 167.

[14] BARD A.J., FAULKNE L.R., Electrochemical Methods, Fundamentals and Applications, John Wiley \& Sons, Inc., New York, 2001.

[15] Soestbergen VAN M., Russ. J. Electrochem.+, 48 (2012), 570. 
[16] Martin H.B., Argoitia A., Angus J.C., Landau

Received 2014-02-19

U., J. Electrochem. Soc., 146 (1999), 2959.

Accepted 2014-05-26 